Tanja Schwarzmüller, Prisca Brosi, Denis Duman, Isabell M. Welpe*

\title{
How Does the Digital Transformation Affect Organizations? Key Themes of Change in Work Design and Leadership**
}

\begin{abstract}
Due to recent technological advances, organizations currently face massive changes of their work design and leadership. Unfortunately, the exact nature of these changes is still unclear as most existing studies were conducted during earlier stages of the digital transformation and the available literature is highly fragmented. To provide an up-to-date overview on the changes in work design and leadership resulting from the digital transformation and to structure our existing knowledge in this domain, we conducted an open-ended online survey with 49 recognized digitalization experts and identified key themes of change. In sum, four key themes of change affecting both work design and leadership emerged, namely changes in work-life and health, the use of information and communication technology, performance and talent management and organizational hierarchies. In addition, two macro-level change dimensions regarding the structure of work and relationshiporiented leadership evolved. While some of the identified changes were partly covered in earlier studies, others have so far not received much attention despite their apparently high relevance in the current stage of the digital transformation. The results of this study therefore provide an important basis for future research and help organizations to strategically prepare for the requirements of the digital age.
\end{abstract}

Keywords: digital transformation, digitalization, information technology, technological advances, work design, leadership

(JEL-Codes: M10, M12, M50)

* Dr. Tanja Schwarzmüller (corresponding author): Chair for Strategy and Organization, TUM School of Management, Technical University of Munich, Arcisstraße 21, 80333 Munich, Germany. E-Mail: t.schwarzmueller@tum.de

Dr. Prisca Brosi: Chair for Strategy and Organization, TUM School of Management, Technical University of Munich. E-Mail: brosi@tum.de

Denis Duman: Chair for Strategy and Organization, TUM School of Management, Technical University of Munich. E-Mail: denis.duman@me.com

Prof. Dr. Isabell M. Welpe: Chair for Strategy and Organization, TUM School of Management, Technical University of Munich; Bavarian State Institute for Higher Education Research and Planning. E-Mail:welpe@tum.de; welpe@ihf.bayern.de.

** Article received: September 29, 2016

Article accepted: November 15, 2017

mrev, 29 (2) 2018, $114-138$

DOI: 10.5771/0935-9915-2018-2-114 


\section{Introduction}

As technology is rapidly progressing, present-day organizations are confronted with massive changes (Colbert, Yee, \& George, 2016). In the current era of ubiquitous computing, starting around the year 2013, information and communication technology permeates organizations and unifies the digital and physical world more closely than ever before. Disruptive technologies such as mobile computing and virtual reality corrupt previously existing boundaries between online and offline settings, creating large-scale networks of people, computers and objects. Sensors embedded in wearable devices and machines constantly generate big data, based on which intelligent software and smart robots make complex decisions and take over previously human tasks. Telepresence systems allow for projecting team members from around the globe into the same meeting room and new communication media make it possible to reach others immediately at any particular point in time (Cascio \& Montealegre, 2016).

These technological changes particularly affect the design of work (Barley, 2015), i. e. the way in which employees work in organizations as well as the conditions under which they do so (Parker, Wall, \& Cordery, 2001). Employees are nowadays often constantly connected to their workplace due to cloud services and mobile devices, a phenomenon profoundly affecting their work and private life (Mazmanian, 2013). In addition, regular teamwork is more and more replaced by work in virtual teams (Gilson, Maynard, Young, Vartiainen, \& Hakonen, 2015), which implies that communication with others takes place via instant messaging, social media and the above-mentioned teleconferencing, while collaboration occurs by means of knowledge-sharing platforms and collaboration tools such as Trello or Slack (Colbert et al., 2016; Haas, Criscuolo, \& George, 2015).

Furthermore, the new developments in the realm of digital transformation also crucially change the way in which leadership is exerted in organizations. As information technology and mobile devices give employees the opportunity to gain immediate access to all kinds of information (Oldham \& Da Silva, 2015) and instant messaging services and social networks allow for direct communication with leaders on all organizational levels (Pfeffer, 2013), leaders' level of power and influence changes dramatically. Alongside, leaders' decision making is increasingly based on the intelligent analysis of big data (Van Knippenberg, Dahlander, Haas, \& George, 2015) instead of on own experience and intuition (McAfee \& Brynjolfsson, 2012). Finally, the fact that more and more employees work from home or in virtual teams also implies that contemporary leaders might need very different skills and behaviors than they did a couple of years ago (Serban et al., 2015).

Taking these recent technological advances and their implications for work design and leadership into account, it is no wonder that research stresses how little we still know about the digital transformation, work design and leadership (Avolio, Sosik, Kahai,, \& Baker, 2014; Parker, Van den Broeck, \& Holman, 2017). Research on 
this topic appears as practically 'still in its infancy' (Cascio \& Montealegre, 2016, p. 365) as most of it was conducted during earlier stages of digitalization (e. g. Barley, 1990; Cascio, 1995; Daft \& Lengel, 1986; Kayworth \& Leidner, 2001; Orlikowski \& Robey, 1991; Zuboff, 1988) and hence focused on technologies nowadays considered as standard (e. g. email, enterprise application systems). In addition, the existing literature is highly fragmented, as most papers focused on one specific topic, but did not aggregate their findings onto a higher conceptual level. This fragmentation makes it difficult to detect larger patterns of change resulting from the digital transformation (Avolio, Walumbwa, \& Weber, 2009; Oldham \& Hackman, 2010).

The goal of this paper therefore is to review, refresh and structure the literature on the effects of the digital transformation on work design and leadership considering the current stage of digitalization to provide an up-to-date overview on this important phenomenon. To do so, we conduct an open-ended online survey, asking renowned digitalization experts to outline the most important changes currently resulting from digital transformation for work design and leadership. Making use of content-analytic coding (Gioia, Corley, \& Hamilton, 2012), we deduct the key themes of change that are relevant today and compare them to those topics dominating the existing literature.

Taken together, our paper makes several important contributions to theory. First, by assessing how the digital transformation currently affects work design and leadership, our paper allows to develop an up-to-date understanding on the changes that the digital transformation implies for work design and leadership (Barley, 2015). Second, by deriving key themes of change occurring in the age of ubiquitous computing and comparing them to the existing literature, this paper structures our so far fragmented knowledge on the digital transformation (Avolio et al., 2009; Oldham \& Hackman, 2010) and helps us to get a better overview on this important topic. In addition, our paper also has valuable practical implications as it can support organizations in preparing for the digital transformation. Our results may for example inform the selection of new employees and leaders in line with the requirements of the digital age (Cascio \& Aguinis, 2008), but also allow for the strategic development of employees and leaders (Day, Fleenor, Atwater, Sturm, \& McKee, 2014).

\section{Effects of the Digital Transformation on Work Design and Leadership: Reviewing Core Topics in Previous Research}

In the following, we will review the core topics that have been in the focus of earlier research on the effects of the digital transformation on work design and leadership. Thereby, we create a basis of comparison with the key themes of change in the current stage of the digital transformation that we will identify in our own expert survey. 
Teleworking is one of the predominant areas that has been addressed by earlier research. It is usually defined in spatial matters, i. e. as 'working outside the conventional workplace and communicating with it by way of telecommunications or computer-based technology' (Bailey \& Kurland, 2002, p. 384). A range of studies has tried to identify antecedents of teleworking, such as demographic variables (Olszewski \& Mokhtarian, 1994) and job characteristics (Mannering \& Mokhtarian, 1995). Likewise, several outcomes of teleworking, such as employees' job satisfaction and performance (Golden \& Veiga, 2005; Gajendran \& Harrison, 2007), have been assessed. Teleworking may affect the work-family interface, with both positive and negative effects being possible (Raghuram \& Wiesenfeld, 2004; Standen, Daniels, \& Lamond, 1999). Related to teleworking is an increased temporal flexibility of employees, as teleworking allows for being connected to one's workplace (Mazmanian, Orlikowski, \& Yates, 2005) and working outside traditional working hours (Mazmanian, 2013). Following from flexible work arrangements, the lines between work and non-work domains have recently been suggested to blur (Reyt \& Wiesenfeld, 2015). This development is likely to increase employees' stress levels (Kelliher \& Anderson, 2010) - a phenomenon that has also been referred to as 'technostress' (Tarafdar, Tu, Ragu-Nathan, \& Ragu-Nathan, 2007). While all of these changes are likely to apply to non-managerial and managerial employees (Mazmanian, 2013), most research has not specifically addressed leadership in this context. The little available research has stressed the importance of high-quality leader-member exchange (Golden \& Veiga, 2008), transformational leadership (Wang \& Walumbwa, 2007) and supportive leader attributions for flexible work use (Leslie, Flaherty Manchester, Park, \& Mehng, 2012) as central prerequisites for the success of teleworking.

Existing research has also dealt with digital technology's potential to substitute employees and leaders. While previously especially middle-skilled jobs such as bank tellers or book keepers were thought as being prone to automation (Autor, Katz, \& Kearney, 2006; Bresnahan, 1999), new research stresses that rapidly progressing artificial intelligence will more and more substitute white-collar workers (Frey \& Osborne, 2017). Yet, next to substituting work formerly conducted by humans, technology may also assist human workers in performing their tasks (Orlikowski \& Robey, 1991), for example when making decisions (Shim, Warkentin, Courtney, Power, Sharda, \& Carlsson, 2002). This applies especially to leadership: Technology may support managerial tasks - such as by simplifying personnel selection by means of big data analysis, as recently suggested by Campion, Campion, Camion and Reider (2016) - but is unlikely to substitute more social leadership functions such as inspiring and motivating followers as well as the highly complex and cognitively demanding work likewise comprised in managerial jobs (Bresnahan, Brynjolfsson, \& Hitt, 2000).

Another prominent research stream has focused on work and leadership in virtual teams, i. e. in 'teams whose members use technology to varying degrees in working 
across locational, temporal, and relational boundaries to accomplish an interdependent task' (Martins, Gilson, \& Maynard, 2004, p. 808). Multiple factors that contribute to virtual teams' effectiveness have been identified, ranging from optimal group size (Gallupe et al., 1992) to task type (Straus \& McGrath, 1994) and team composition (Kayworth \& Leidner, 2001). Media richness theory (Daft \& Lengel, 1986) points to the importance of the chosen communication medium, as different media (e. g. telephone, email) possess different levels of richness and convey information in a more or less equivocal way. Research has also asked how to exert e-leadership (Avolio et al., 2014) or leadership in virtual teams (Hertel, Geister, \& Konradt, 2005; Malhotra, Majchrzak, \& Rosen, 2007). Here, the importance of inspirational leadership and transparent reward systems has been stressed (Hoch \& Kozlowski, 2014; Joshi, Lazarova, \& Liao, 2009). Moreover, these contexts might force leaders to convey more responsibility to team members (Duarte \& Snyder, 1999), resulting in leaders orchestrating rather than controlling followers (Kayworth \& Leidner, 2001).

Another strand of research has dealt with the question how technology adoption in organizations changes the skills required from employees and leaders. As technological advances contribute to more knowledge-based organizations (Sinha \& Van de Ven, 2005) and especially routine work is automated (Autor et al., 2006), skilled employees are becoming more important (Brynjolfsson \& Hitt, 2000). Competencies that seem to matter are problem solving (Parker et al., 2001), creativity (Frenkel, Korczynski, Donoghue, \& Shire, 1995), efficiently dealing with large amounts of information (Van Knippenberg et al., 2015), social skills (Frey \& Osborne, 2017) and fast decision making (Perlow, Okhuysen, \& Repenning, 2002). For leaders, tolerating ambiguity as well as inspiring followers seem to become more crucial skills in the digital age (Cascio \& Montealegre, 2016).

A final domain predominantly analyzed in older publications is the impact of digital technology on power structures in organizations. Early research (e. g. Bloomfield \& Coombs, 1992; Davenport \& Short, 1990; Orlikowski \& Robey, 1991) has argued that technology may lead to both a centralization of power (as technology can reinforce classical power structures) and a decentralization of power (as information becomes more distributed within the organization). Often, arguments in favor of the former perspective have been provided (e. g. Foster \& Flynn, 1984; Zuboff, 1988). A similar dichotomy emerged in relatively newer papers: On the one side, digital technologies help to identify those with most knowledge in a given field, shifting power from those with legitimacy to those with expertise (Leonardi, 2007). On the other side, computer-aided monitoring tools allow for increased managerial control and a strengthening of existing hierarchies (Dewett \& Jones, 2001).

Taken together, the main topics addressed by research in earlier stages of the digital transformation can be summed up as revolving around teleworking, technostress, automation and assistance by digital technologies, virtual teams, and, to a smaller 
extent, changed skill requirements and power structures. To find out whether these topics are still relevant in the current age of ubiquitous computing as well as to identify potential additional changes affecting work design and leadership nowadays and to thereby structure our knowledge in this important domain, our expert survey, which is described in the following, aimed to answer the following research questions:

Research question 1: How does the digital transformation change work design?

Research question 2: How does the digital transformation change leadership?

\section{Method: Expert Survey}

Answering our research questions requires in-depth knowledge. We hence followed other researchers' recommendation (Chiravuri, Nazareth, \& Ramamurthy, 2011) to use an open-ended survey of renowned digitalization experts to identify key themes of change and hence to gain an in-depth understanding of this phenomenon (Bansal \& Corley, 2012).

\section{Sample}

Our study sample consisted of 49 German-speaking digitalization experts. To encompass a variety of viewpoints and enhance the transferability of our results, we chose experts from different domains: $57.4 \%$ worked in business, $31.9 \%$ in research, $6.4 \%$ in associations, foundations, or unions, and $4.3 \%$ in politics. Experts were identified via a comprehensive internet search targeting indicators of expertise on digitalization. They were e. g. responsible for advancing the digital transformation in companies or foundations, were members in political committees on the future of work, ran research centres on digital leadership or had written scientific papers and popular books on the digital transformation. Experts were invited to the survey via email and telephone. Confirming their expertise, participants indicated that they intensely dealt with the digital transformation $(M=6.64, S D=0.72)$ on a scale from 1 (not at all) to 7 (very much). Around $70 \%$ of our experts were male, their mean age was 47 years $(S D=10.75)$. Eighty-nine percent occupied a leadership role, mostly $(65.8 \%)$ in upper management, where they led around nine employees $(S D=121.95)$.

\section{Procedure}

Our study was conducted via an open-ended online questionnaire. Experts were informed that the questionnaire dealt with changes resulting from digitalization. The first question was 'How do work and work design (the way in which employees work as well as the conditions under which they do so) in organizations change as a result of the digital transformation?'. The second question was 'How does leadership (the way in which leaders deal with their employees and make them contribute to 
organizational goals) change as a result of the digital transformation?'. Experts were asked to name at least six changes resulting from the digital transformation for work and leadership and to then describe these in more detail. On average, the descriptions of these individual changes were 30.8 words long $(S D=57.72)$.

\section{Coding Strategy}

We analysed experts' answers using the inductive content analytic coding strategy outlined by Gioia and colleagues (2012).

Step 1: Provisional category scheme. Coder 1 went through around $50 \%$ of the interview material. Frequently mentioned topics were used to derive first-order codes, which still very closely reflected the experts' perspectives (e. g. 'work can increasingly be conducted in a spatially flexible manner'). We also derived initial second-order categories, aggregating first-order codes to a higher conceptual level (e. g. 'increased spatial flexibility').

Step 2: Revision of the category scheme. Coder 2 applied this preliminary category scheme to the rest of the interview material. If it did not fit into the existing categories, new categories were constructed while existing ones were revised. The coders discussed these changes to ensure that the resulting categories accurately reflected the material.

Step 3: Coding of the complete material. Both coders then coded all of the material independently. Cohen's Kappa (Landis \& Koch, 1977), an index for interrater reliability, indicated full agreement $(\kappa=.84)$. Remaining differences were resolved through discussion.

\section{Step 4: Deduction of overarching dimensions and aggregation to key themes.} After coding, we identified overarching dimensions emerging from our data, relating first- and second-order categories to higher-level concepts. For example, we created the dimension 'changes in work-life setup' to subsume the related categories of employees' increased temporal and spatial flexibility and their increased work-life balance. Together with the dimensions of 'increased leader health management' and 'higher job demands', it was aggregated to the key theme of 'work-life and health'. Labels for overarching dimensions and key themes were chosen to best reflect their underlying categories and to be distinct from one another.

Step 5: Identification of potential interrelations between changes in work design and leadership. As common in qualitative data analysis (Bansal \& Corley, 2012), while coding we came to an insight not initially pursued with our study, namely that the identified changes in work design and leadership seemed to be associated with each other. There were indications for two types of interrelations: 1) reciprocal relationships in which changes in work design affected leadership and changes in leadership, in turn, affected work design; 2) unidirectional relationships in which changes in work design preceded changes in leadership or vice versa. In line 
with previous research (e. g. Byron \& Laurence, 2015), we argue for these relationships based on our empirical data, and, if necessary, based on existing research.

\section{Results: Key Themes of Change in Work Design and Leadership}

Our expert survey revealed four key themes of change in work design and leadership as a result of the digital transformation. The first key theme revolves around changes in the work-life and health domain, implying an altered relationship between work and private life. The second key theme implies changes resulting from the use of information and communication technology which affect working modes and communication/collaboration. The third key theme is concerned with performance and talent management in organizations, as digitalization changes competency requirements as well as performance measurement and management. The fourth key theme deals with organizational hierarchies, as employees take over more responsibility and leaders display different types of influence behaviour in the age of ubiquitous computing. In addition, two macro-level dimensions of change emerged that seemed to arise from all of the identified key themes of change in work design and leadership. The first of these two dimensions are structural changes of jobs, i. e. changes in job profiles and the emergence of new jobs. The second macro-level change dimension is relationship-oriented leadership, consisting of both a more individualized leadership style and team- and network-oriented leader behaviour. Finally, as described above, there seem to be different types of interrelations between changes in work design and leadership. Figure 1 graphically displays the identified key themes of change and their interrelations as well as the two macro-level change dimensions, all of which are described in more detail in the following. 
Figure 1: Changes Resulting for Work Design and Leadership Due to the Digital Transformation.

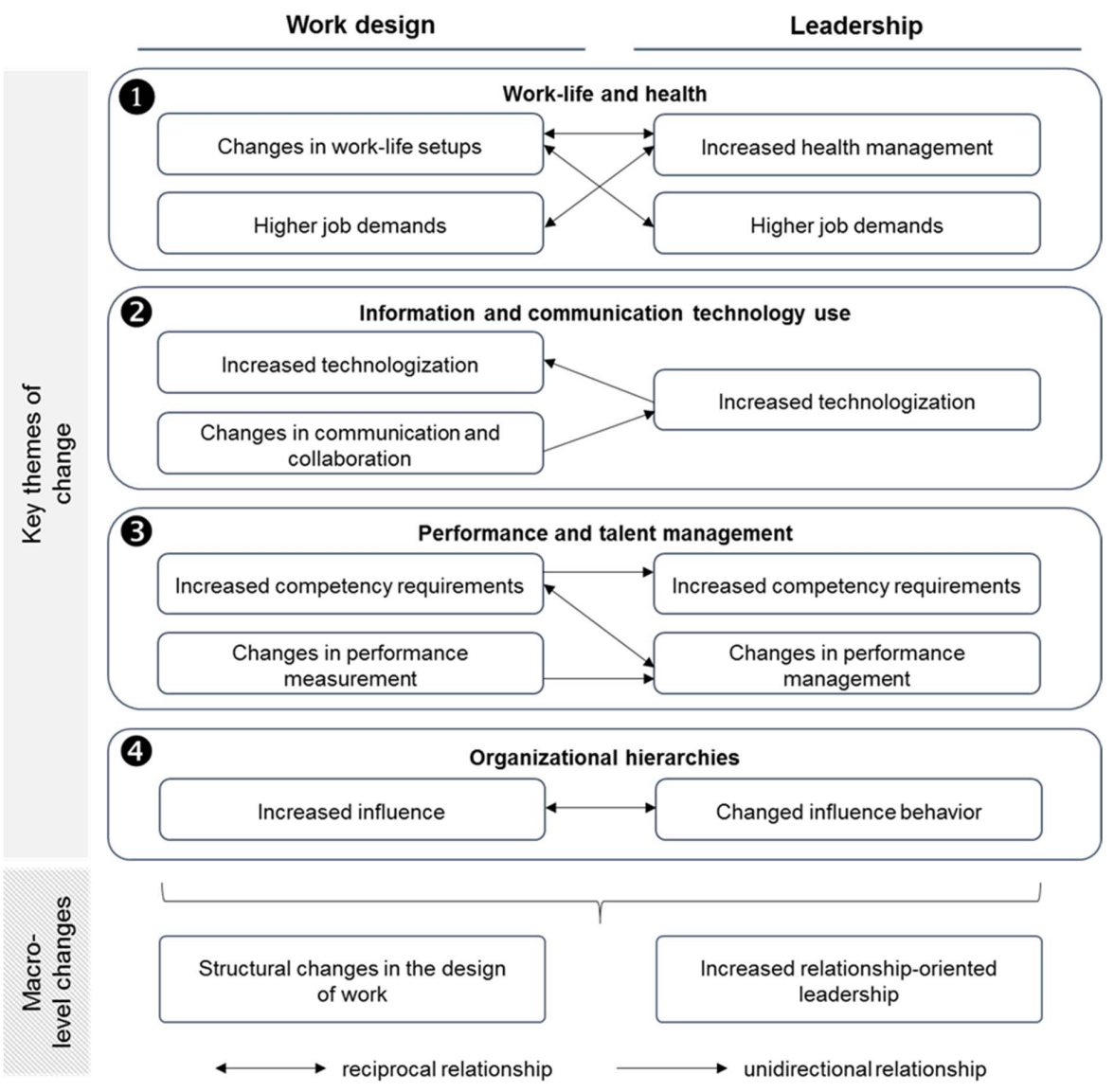

\section{Key Theme 1: Changes in Work-Life and Health}

The first key theme reflects changes in the domain of work-life and health. It encompasses changes in employees' work-life setup, a higher necessity for health management on part of leaders, and an increase in both employees' and leaders' job demands.

Employees' work-life setup and health management. The digital transformation continues to affect employees' work-life setup, i. e. the relationship between their work and private life, predominantly by increasing their spatial and temporal flexibility. With regard to spatial flexibility, employees are less bound to their regular workplace, as one expert outlined: 'The workplace of the future will usually also be an office workplace. However, this does not necessarily mean that the workplace will be located in a corporate company building. [...] Home-office-arrangements will be- 
come more attractive as personal households become increasingly equipped with the most modern communication technologies' [E22]. Hence, being physically present in the workplace becomes less warranted for many employees. Additionally, digital technologies increasingly allow employees to work when they want to. Finishing important projects in the evening or on weekends becomes normal, office hours lose importance: 'Work is no longer defined by working hours between 8 am and $6 \mathrm{pm}$ but takes place around the clock, with breaks during traditional core time' [E38]. In the current age, results matter - not where and when they are achieved. These developments bring opportunities and risks: On the one hand, employees may benefit from increased work-life balance, as working when and where convenient allows to accommodate to private needs (e. g. childcare). On the other hand, always being able to reach out to work-related materials may increase employees' availability and establish a norm of constant connectivity:

'Increasing pressure to be available $24 / 7$ and a shorter reaction time - the "always-on" mentality is transferred to working life; [...] employees possess mobile devices, enabling them to reply to work messages and emails around the clock, resulting in a higher expectation to be always available and to react quickly to inquiries.' [E29]

Overall, this leads to a lack of boundaries between work and private life, with 'private life becoming professional, and professional life becoming private' [E42].

Changes in employees' work-life setups also necessitate leaders to pay increased attention to employees' health and to allow for breaks: 'Work and private life are largely merged. It will be important to create digital freedom that is respected by leaders' [E22]. Thus, leaders have a crucial role in curtailing followers' stress, such as by making explicit arrangements regarding work during non-office time: 'Leaders need to ensure that the flexibility of work time and space does not lead to a perceived or actual overload of employees. For instance, it is possible to define to what extent emails and messages should be processed on weekends' [E8]. Importantly, leaders should also role-model these arrangements (e. g. by not sending emails on weekends). Taken together, there thus seems to be a reciprocal relationship between work design and leadership: Changes in employees' work-life setup (such as the lack of boundaries) seem to require more health management behaviour on part of leaders. In case leaders actually engage in health management, this in turn is likely to benefit employees' work-life setup, as previous research has shown (Butts, Hurst, \& Eby, 2013).

Employees' and leaders' job demands. Changes in the key theme of work-life and health are also reflected in higher job demands for employees. The first important demand is an increase in the complexity of employees' work, as modern communication systems confront employees with very high information density. Not losing track becomes a central challenge: 'Due to electronic communication channels, the amount of available information increases continuously and challenges many employees to maintain an efficient working method and to avoid getting distracted by 
emails and social media feeds' [E29]. Enhanced complexity also relates to increased insecurity. The digital transformation currently forces organizations to be disruptive (i. e. to come up with radically new ideas). Yet, predicting the outcomes of one's actions is difficult when there is no clear path to success anymore. In addition, higher speed becomes a central job demand due to an increased pressure for innovation: 'With the acceleration of the working world, time to market becomes more relevant as today's innovations spread rapidly. [...] An organization that is three months slower than its competitors will be confronted with an already saturated market with high entry barriers' [E38]. All of these factors (complexity, insecurity and time pressure) are likely to increase employees' workload and also their experienced stress: 'The amount of data and the higher frequency of decisions often overburdens employees. In addition, employees often do not have sufficient overview (big picture) [...]. This causes stress' [E13]. Employees' job demands might have a reciprocal relationship with leaders' health management behaviour, as leaders might feel that they have to manage employees' health to help them deal with their increased job demands: 'Leadership needs to [...] take on an orientation and steering function to avoid overload and excessive demands' [E17]. When leaders engage in health management, this might in turn reduce employees' perceived job demands as their leaders' support might make employees feel better equipped to cope with their job requirements (Butts et al., 2013).

Leaders likewise experience higher job demands. The increased pressure for innovation forces them, just as their employees, to act with higher speed and to 'take managerial decisions fast' [E25]. In the same way, enhanced availability might also play a role for leaders, increasing stress and pressure. Furthermore, the increased temporal and spatial flexibility of employees and their higher availability requirements are likely to also increase the amount of time during which leaders need to be available for their employees: 'Leadership around the clock: With ordering, production and delivery being possible at all times, it is necessary to lead at all times' [E21]. As leaders constitute role models for their employees and state norms for expected workplace behaviour (Bandura, 1977), their long availability could in turn further exacerbate employees' availability requirements and thereby negatively affect their worklife setup, leading to a cycle of mutual reinforcement. In consequence, a reciprocal relationship between employees' changed work-life setup and leaders' job demands emerges.

\section{Key Theme 2: Changes in the Use of Information and Communication Technology}

The second key theme of change relates to the use of information and communication technology in organizations. It encompasses an increased technologization of work and leadership as well as changes in workplace communication and collaboration. 
Technologization of work and leadership. Information technology not only influences where and when employees work, but also how they work due to an increased support through machines and information technology. Big data and tools for visualizing them increase control over work processes and allow for more informed decision making: 'A high number of data are made available on screens, electronic dashboards, and mobile devices, which will make detailed processes and even single stages of work flows controllable' [E6]. While technology simplifies many tasks, it may also reduce employees' freedom due to an increased standardization: 'it is not possible anymore to just make things differently in case one wants to' [E19]. Augmented reality gains importance, for example providing employees with personalized information for their tasks: 'Thanks to machine learning, data mining etc. assistance systems can be more strongly tailored to employees' individual competencies' [E30]. Electronic assistance systems hence provide optimal support to employees, e. g. facilitating organizational learning: 'Intelligent and adaptive software trains employees, ranging from clerks to managers: step-by-step training as adaptive learning can be adjusted to recipients' individual progress via monitoring and tracking' [E34]. Yet, employees might not only be supported, but ultimately be replaced by technology as work continues to be automated. This particularly applies to administrative tasks but might also affect more complex and social domains: 'With increasing machine-to-machine communication, more intelligent algorithms (AI) and more efficient energy storage systems, computers or robots can take over more and more tasks that were previously carried out exclusively by human resources. This applies even to very "human" tasks like nursing' [E11]. Reflecting the shift to knowledge work, 'the tasks that remain [...] are highly complex tasks that put highest requirements on human intellect and education' [E11].

Leaders likewise receive increased support through machines and information technolo$g y$. This support spans a wide domain of leadership functions, such as decision making: 'For organizational tasks, management information systems will provide more data to support decision-making in the future. Thus, management decisions can be made faster and on a more informed basis' [E25]. Yet, big data analytics also provide leaders with various further opportunities: '[...] analysing the relationship between the frequency of accidents and certain production stages. This allows more targeted interventions for avoiding accidents. Or: Analysing fluctuation allows conclusions about leadership behaviour, claims of certain employee groups etc.' [E19]. Increased communication via new media assists leaders' communication with team members. Interestingly, none of our experts thought that leadership would be automated, reflecting the belief that leaders engage in functions that cannot easily be substituted by machines. Regarding interrelations, it seems that there is a unidirectional relationship between the technologization of leadership and that of work, as leaders working extensively with information technology might expect their employees to do so as well, establishing norms of expected workplace behaviour. Employees, in contrast, are probably less able to influence leaders' technology use, as 
they usually have less discretion to decide about information technology use at work (Lewis, Agarwal, \& Sambamurthy, 2003).

Workplace communication and collaboration. Finally, information and communication technology use affects collaboration and communication in organizations. In general, the importance of teamwork increases, as 'knowledge as a resource can only be developed and advanced together. Communication and cooperation serve as a prerequisite' [E42]. Facilitated by digital technologies and communication via new media, new types of teamwork will emerge. As can be expected, 'in international organizations working in virtual teams will already constitute the default during the next couple of years' [E22]. In addition, former departmental structures are likely to be replaced by project-based, self-organizing teams: 'In the digital economy, [hierarchies] are too inflexible and slow. They are superseded by networks, in which experts with suitable skills come together temporarily for a task' [E11]. Likewise, collaboration between different organizations grows, as 'the increasing interconnectedness and relocation of value creation requires effective and purposeful communication and negotiation with a multitude of partners' [E18]. Changes in employees' communication and collaboration might be unidirectionally related to the technologization of leadership, as the increased work in virtual teams might force leaders to communicate more via new media: 'Necessarily, [there is] more leadership over distance and therefore a use of more diverse communication channels' [E29].

\section{Key Theme 3: Changes in Performance and Talent Management}

The third key theme reflects changes in performance and talent management. It encompasses increased competency requirements for both employees and leaders as well as changes in performance measurement and management.

Competency requirements for employees and leaders. The increased technologization of work leads to an increased need for IT competencies, with 'basic computer knowledge being required for almost any job' [E38]. Moreover, as outlined above, particularly routine tasks are automated, confronting employees with increased cognitive demands and therefore a higher need for creativity and problem-solving competencies to successfully deal with those tasks remaining to them: '[...] knowledge workers will be relieved from routine tasks, while at the same time the percentage of tasks that require a high degree of creativity and initiative and that constitute high value-added increases' [E22]. In addition, the digital transformation currently leads to highly dynamic markets, pressuring employees to continuously adapt to new situations and increasing their need for agility. Relatedly, there is also an increased need for lifelong learning: 'Lifelong learning is a necessity. Nowadays, knowledge has a half-life of a few years. There are no more jobs that can be performed based on knowledge from 10 years ago' [E38]. Finally, in line with employees' higher job demands, higher levels of resilience become vital: 'Humans' psychological resilience and 
strength [...] becomes more and more important to be able to meet the various requirements of the working world' [E20].

Regarding competency requirements for leaders, employees previously described frequent work in virtual and globally dispersed teams requires leaders to possess sufficient intercultural and language competencies and to be able to lead from a distance. Behaviours that leaders have previously relied upon might no longer work in such contexts: 'I just can't lead through presence any longer. I simply can't go somewhere quickly and look around and thump the table. [...] Hence, I need to lead from a distance and possess the necessary instruments and related behavioural patterns' [E41]. In line with the enhanced uncertainty and complexity characterizing work in today's digital world, leaders need to be able to manage uncertainty and complexity and to actively handle and initiate change in their organization: 'The complexity and quantity of changes with which leaders are confronted are on the rise [...] Leaders need more competencies in dealing with changes on their own and in communicating stability and continuity to their employees, while things are changing constantly' [E17]. Moreover, the higher need for IT competencies and an increased need for lifelong learning named as competency requirements for employees were also stressed for leaders. Taken together, one can assume a unidirectional relationship between employees' and leaders' competency requirements: As employees need to be agile and creative and have to constantly change and develop themselves, leaders might likewise have to more actively promote and allow for such changes (e. g. by establishing a climate for change and reducing barriers) and learn more themselves to provide direction and optimal support for their employees (McCann, Selsky, \& Lee, 2009).

Performance measurement and management. Digitalization currently also changes performance measurement and management in organizations. Technologies such as virtual collaboration tools and shared documents lead to higher performance transparency: 'In the digital workplace, it becomes more transparent for employees and leaders who does what in the company, which topics are currently dealt with, what the current status is [...] the contribution of individual employees becomes visible and measurable' [E21]. In line with this transparency and employees' temporal and spatial flexibility, leaders display a higher output orientation (i. e. a stronger focus on results) when evaluating employees' performance. This points to a unidirectional relationship between performance measurement and performance management, as the new possibility to constantly track and measure employees' performance might motivate leaders to actually focus more on employees' output: 'It's less about face-time than about what followers deliver' [E45]. Also relating to performance management, the higher competency requirements that employees face in the digital age make personnel development a more important leadership task. Developing followers in turn is likely to ensure their long-term psychological and physical health: 'Missing competencies of employees need to be recognized and compensated for by means of training. [...] Employees' strengths (competency profile) need to 
be known and aligned with the requirements. People become ill if they are over- or under-challenged' [E16]. This pattern of results indicates a reciprocal relationship between employees' increased competency requirements and leaders' performance management: Leaders might engage in more personnel development to help their employees cope with increased job demands; developing employees should in turn reduce their felt job demands by helping employees to better live up to the requirements of their job (Arthur, Bennett, Edens, \& Bell, 2003).

\section{Key Theme 4: Changes in Organizational Hierarchies}

The fourth key theme relates to changes in organizational hierarchies and involves increased employee influence and changed leader influence behaviour.

Increased employee influence and changed leader influence behaviour. Experts strongly agreed that, in its momentary stage, the digital transformation increases employees' influence in organizations. Due to digital tools (e. g. feedback apps), an increased participation of employees in organizational decision making is possible, allowing 'real-time involvement in a vast variety of topics and decisions' [E17]. As employees in the current stage of digitalization are mainly knowledge workers (see above), they might even demand to participate in decision-making: 'Employees can be better involved and also have the expectation of being involved' [E13]. This relates to employees experiencing increased autonomy at work, meaning that they have more leeway to make decisions on their own: 'Control activities previously exerted by leaders vanish. Employees working on a topic take the responsibility for the quality of their work' [E15]. Considering the high complexity and uncertainty of the current digital world, 'decisions can be made less top down' [E23] as leaders often do not have the capacities and knowledge to react fast enough:

'In a classical, non-digital organization communication takes place radially via the leader. Due to the higher communication density in the digital society this does not scale anymore. Therefore, as much as possible needs to be delegated completely to the team, so that fast decision paths resulting from decentralized decisions do not thwart the speed of the digital world.' [E32]

Taking responsibility for one's work in turn is facilitated by increased information access (e. g. internal wikis, internet, instant messaging) and enhanced information transparency, which 'makes it easier to find contact persons for specific topics in the company. Direct contact is possible without going through managers, and knowledge and information become more visible and easier to detect, so that having a lead on knowledge and information becomes less of a status characteristic for leaders' [E21]. Overall, the digital transformation at present thus seems to flatten hierarchies.

The changes described so far already imply that leaders' influence behaviour over followers changes as well. Leaders are expected to lead in a more participatory way by actively incorporating their followers' ideas during decision-making. Decisions are frequently 'based on collective intelligence' [E4], causing leaders to distribute lead- 
ership functions in their team depending on requirements and expertise. Hence, leaders are likely to grant more autonomy to followers. In line, their new role could be described as outlining goals but letting employees decide how to reach them: 'It is not the leader's job anymore to define and distribute tasks, but to define a goal and let employees find their own way to reach this goal [...]' [E40]. This obviously requires more trust in employees, i. e. to 'let go and to trust in the competencies of [...] employees, who typically are more competent in their area of expertise' [E32]. Yet, demanding that employees take over leadership tasks also increases the importance of inspiring and motivating followers - factors that might in turn increase employees' willingness to contribute by 'triggering intrinsic motivation' [E4]. Taken together, there thus seems to be a reciprocal relationship between employees' increased influence and leaders' changed influence behaviour, as digitalization provides more autonomy to employees, which in turn necessitates more participatory behaviour on part of leaders: 'Due to the digital transformation, more opportunities to work autonomously emerge for employees. Leaders need to offer and engage in these opportunities' [E8]. In case leaders provide autonomy and trust to employees, this in turn is likely to reinforce employees' influence at work (Lorinkova, Pearsall, \& Sims, 2013).

\section{Macro-Level Dimensions of Change: Structural Changes of Work and Increased Importance of Relationship-Oriented Leadership}

Finally, our results revealed two dimensions of change in which work design and leadership are affected on a macro-level and that seem to arise from all of the identified key themes of change - a reasoning that we elaborate on in detail in the following.

Structural changes. The first macro-level change dimension consists of structural changes in the design of work, i. e. changes in existing jobs' profiles as well as the emergence of new types of jobs. The higher job demands and competency requirements as well as the increased influence that employees are granted by their leaders suggest that job profiles will change in the digital age. This development is fostered by the use of information and communication technology at work, for example by the automation of production: 'Skilled workers in a smart factory will carry out less diverse tasks on a higher number of machines and monitor machines based on signals instead of visual inspection. They will turn more into problem solvers and fix malfunctions in cooperation with machines' [E6]. Changed job profiles also seem to occur for white collar workers, such as HR managers: 'Time recording/holiday requests are processed automatically, possibly even in employee self-service. Manual time recording by the clerk is no longer necessary. He [the clerk] has more time for qualitative HR work, etc.' [E19]. As routine and simple work is taken over by technology, more demanding work comes to the fore of most jobs. Yet, digital transformation not only means that existing job profiles change, but also that new types of jobs such as 'digital journalism, blogging, online marketing, app development' 
[E29] are likely to emerge. In sum, structural changes of work hence seem to arise as a logical consequence of the key themes of change in work design and leadership.

Increased importance of relationship-oriented leadership. The second macro-level dimension of change is the increased importance of relationship-oriented leadership. In the current stage of the digital transformation, employees need to cope with higher job demands and competency requirements as well as more challenging work-life-dynamics. In addition, leaders provide them with more influence and at the same time focus strongly on achieved results. High relationship-orientation on part of leaders seems crucial to support employees to meet these challenges. In this vein, coaching and enabling behaviour by which leaders promote employees' development through advice and by providing resources might assist employees to cope with their increased job demands and influence, as it helps them to overcome challenges that they experience when handling tasks autonomously: 'Employees should be empowered to solve tasks on their own. In the event that they encounter difficulties, the leader ought to intervene in a coaching manner, and a solution should be developed together' [E40]. In addition, individualized consideration (i. e. focusing on followers' needs and leading them in a personalized way) seems to become more crucial: Particularly employees' higher spatial flexibility and work in virtual teams makes it necessary for leaders to 'not only replace presence with digital opportunities, but also invest in personal relationships' [E17]. Next to investing in relationships with individual followers, increased networking behaviour by leaders is required to achieve optimal results: 'Leadership means organizing a network: leadership must ensure that the best competencies for a given task come together and work together efficiently' [E7]. Doing so may help employees to autonomously deal with their tasks, to cope with higher job demands and competency requirements and to fulfil the high output-expectations of their leader. Additionally, teambuilding on part of leaders gains importance, as followers often work in dynamic teams in which interpersonal bonds are less likely to emerge: 'Due to agile organizational structures, teambuilding [...] becomes a constant challenge' [E5]. The same is true for virtual teams or employees making use of flexible work arrangements: 'If I don't see my employees on a daily basis anymore, $[. .$.$] how can I create intimacy and collective$ commitment in a dispersed work environment?' [E17]. Taken together, relationship-oriented leadership hence seems to constitute an important answer to help employees cope with the key changes identified above.

\section{Discussion}

\section{Contributions to Theory}

Against the background of dramatic technological developments in recent years (Cascio \& Montealegre, 2016), the goal of our paper was to develop an up-to-date overview on the changes that digitalization implies for work design and leadership and to structure our so far fragmented knowledge on the implications of the digital 
transformation. In the following, we will summarize our results in relation to this goal.

\section{Key themes of change and macro-level change dimensions in work design and} leadership as a result of the digital transformation. Taken together, four key themes of change in work design and leadership emerged from our expert survey: Changes with regard to 1) work-life and health (i. e. changed work-life setup, higher importance of health management, increased job demands for employees and leaders), 2) the use of information and communication technology (i. e. increased technologization of work and leadership, changed communication and collaboration), 3) performance and talent management (i. e. increased competency requirements for employees and leaders, changes in performance measurement and management) and 4) organizational hierarchies (i. e. increased employee influence, changed leader influence behaviour). In addition, the digital transformation instils macro-level changes regarding the structure of work (i. e. changes in job profiles, new types of jobs) and the importance of relationship-oriented leadership (i. e. more coaching and enabling, more individualized consideration, increased networking behaviour, more teambuilding).

With this up-to-date overview on the changes resulting from the digital transformation for work and leadership our paper closes an important research gap frequently highlighted by other researchers (e. g. Avolio et al., 2014; Cascio \& Montealegre, 2016; Parker et al., 2017). Moreover, the identified key themes of change and macro-level changes also help to better structure the existing literature, to which we will subsequently compare our results.

Comparison of the identified change themes with those topics dominating the literature. Similarities appear when comparing our results with those topics attracting most attention in earlier research, most of them in the key theme of work-life and health. Temporal and spatial flexibility resulting from the opportunity to engage in teleworking (e. g. Bailey \& Kurland, 2002; Golden \& Veiga, 2005) as well as their effects on work-life balance (Raghuram \& Wiesenfeld, 2004; Standen et al., 1999) and the blurring of boundaries between different life domains (Reyt \& Wiesenfeld, 2015) have previously been a major focus and also emerged in our expert survey. Several of the job demands highlighted by our experts (increased workload, speed and stress) were also outlined by earlier research (Kelliher \& Anderson, 2010). In the key theme of technology use, we replicated the finding that routine tasks, but increasingly also more complex tasks are prone to automation (Bresnahan, 1999; Frey \& Osborne, 2017), and that digital technologies provide important support to employees and leaders (Bresnahan et al., 2002; Orlikowski \& Robey, 1991), e. g. during decision making (Shim et al., 2002). In addition, a popular topic in previous research (e. g. Duarte \& Snyder, 1999; Malhotra et al., 2007) also repeatedly emerging in our survey was work and leadership in virtual teams (and, relatedly, communication via new media). Regarding the key theme of performance and talent management, ear- 
lier studies pointed to the competency requirements of problem solving (Parker et al., 2001), creativity (Frenkel et al., 1995) and information processing (Van Knippenberg et al., 2013), which remain important today. Finally, earlier research on the key theme of organizational hierarchies also argued that computer-aided monitoring tools allow for increased managerial control (e. g. Dewett \& Jones, 2001).

While several topics in the spotlight of earlier research hence remain important in the stage of ubiquitous computing, several domains did not receive much attention in previous literature but seem to exert a decisive influence on work design and leadership nowadays, confirming that re-examining the influence of the digital transformation on work design and leadership is a worthwhile endeavour. Regarding the key theme of work-life and health, health management on part of leaders seems crucial to ensure that followers remain well in digital working environments. In addition, higher complexity and insecurity seem to constitute job demands that should receive more attention in the future. Regarding the key theme of technology use, we notice an increased relevance of teamwork for generating innovation and achieving high performance. Particularly new types of teamwork, namely dynamic networks and cross-organizational teams, could constitute an interesting avenue for further research. In addition, adaptive support tools that dynamically take users' progress and needs into account are a rather new development with potentially wide-ranging implications (e. g. for employee training). Relating to the key theme of performance and talent management, leaders' increased output orientation and necessity for personnel development become more relevant today. Regarding the key theme of organizational hierarchies, an interesting pattern of results emerged: While previous research stressed that digitalization both reinforces and weakens existing hierarchies (e. g. Bloomfield \& Coombs, 1992; Davenport \& Short, 1990), our results strongly suggest that organizational hierarchies will flatten as employees gain more autonomy and participate in organizational decisions. Relatedly, participative leadership gains relevance. Finally, both of our macro-level change dimensions (structural changes of work and relationship-oriented leadership) are topics of currently high importance that have not been sufficiently considered in relation to digitalization. In this area, future research might e. g. analyse whether relationship-oriented leadership buffers potential adverse effects resulting from increased job demands.

Taken together, this comparison of our results with previous research reveals topics that remain important in the current stage of the digital transformation, but also highlights areas that recently seem to gain momentum and therefore constitute valuable starting points for future research.

\section{Contributions to Practice}

Our paper also has important practical implications. Many organizations struggle to make the best of the digital transformation (Fitzgerald, Kruschwitz, Bonnet, \& Welch, 2014). Our results may prove valuable for them by increasing awareness for 
the central changes following from the digital transformation. Thereby, they can inform personnel selection to ensure that new recruits have the necessary skills to thrive in the digital age (Cascio \& Aguinis, 2008). A special focus here should lie on resilience, a trait that helps to exhibit high performance despite increased availability and job demands (Youssef \& Luthans, 2007), and on problem-solving skills, creativity, agility, willingness to learn and the readiness to take over responsibility. When recruiting leaders, organizations should search for persons willing to empower employees and to display relationship-orientation. Organizations may also use our results to adjust personnel development (Day et al., 2014). It e. g. seems worthwhile to teach employees how to efficiently work in virtual, self-organizing or crossorganizational teams. Leaders in turn should be taught how to empower employees without overburdening them and be trained in health management. Finally, organizational culture should be transformed to a culture of involvement, in which decisions are taken together, a culture of innovation, that ensures agility based on the acceptance of suggestions, and a culture of training, in which staff is constantly developed (Patterson et al., 2005).

\section{Limitations and Implications for Future Research}

Despite our paper's valuable contributions, it also has limitations. While our sample is large for an expert survey (Chiravuri et al., 2011), it is based in the German culture area. Hence, one might question whether our results contain all changes occurring in work design and leadership as a consequence of digital transformation. As in all qualitative studies (Pratt, 2008), absolute completeness is hard to achieve. Hence, we do not claim that we have captured all changes that could possibly occur, but that we have captured key themes of change that take place in the digital age. One could also ask to which degree our results are transferable to other countries. In favour of transferability, Germany's degree of digitalization resembles that of other advanced countries (e.g., United Kingdom, United States, South Korea; Baller, Dutta, \& Lanvin, 2016), in which work and leadership might thus be similarly affected by digitalization. Nevertheless, future research would benefit from replicating our study in other countries to provide definite evidence for this assumption.

Another potential limitation is that our study deals with changes in work design and leadership but does not employ a longitudinal study design that is able to prove causal effects of the digital transformation on work design and leadership. While it would be valuable to replicate our results in a longitudinal study, researchers agree that qualitative studies are suitable for building theoretical frameworks on change processes in organizations (Byron \& Laurence, 2015; Gioia et al., 2013). Our results may thus provide an indication of which dimensions of change should be taken into account in quantitative replication studies. 


\section{Conclusion}

With this paper, we provide an up-to-date overview on the changes resulting from the digital transformation for work design and leadership and at the same time give structure to the highly fragmented existing literature. Our four key themes of change revealed both topics from earlier research remaining important today as well as new topics that seem to gain relevance in the current stage of digitalization. Additionally, two so far largely neglected macro-level change dimensions emerged, providing valuable directions for future research and helping organizations to prepare for the requirements of the digital age.

\section{References}

Arthur, W., Bennett, W., Edens, P. S., \& Bell, S. T. (2003). Effectiveness of training in organizations: A meta-analysis of design and evaluation features. Journal of Applied Psychology, 88, 234-245.

Autor, D. H., Katz, H. L., \& Kearney, M. S. (2006). The polarization of the U.S. labor market. American Economic Review, 95, 189-194.

Avolio, B. J., Sosik, J. J., Kahai, S. S., \& Baker, B. (2014). E-leadership: Re-examining transformations in leadership source and transmission. The Leadership Quarterly, 25, 105-131.

Avolio, B. J., Walumbwa, F. O., \& Weber, T. J. (2009). Leadership: Current theories, research, and future directions. Annual Review of Psychology, 60, 421-449.

Bailey, D. E., \& Kurland, N. B. (2002). A review of telework research: Findings, new directions and lessons for the study of modern work. Journal of Organizational Behavior, 23, 383-400.

Baller, S., Dutta, S., \& Lanvin, B. (2016). The global information technology report 2016: Innovating in the digital economy. Geneva, Italy: World Economic Forum.

Bandura, A. (1977). Social learning theory. Englewood Cliffs, NJ: Prentice Hall.

Bansal, P., \& Corley, K. (2012). Publishing in AMJ_Part 7: What's different about qualitative research? Academy of Management Journal, 55, 509-513.

Barley, S. R. (1990). The alignment of technology and structure through roles and networks. Administrative Science Quarterly, 35, 61-103.

Barley, S. R. (2015). Why the internet makes buying a car less loathsome: How technologies change role relations. Academy of Management Discoveries, 1, 5-35.

Bloomfield, B. P., \& Coombs. R. (1992). Information technology, control and power: The centralization and decentralization debate revisited. Journal of Management Studies, 29, 459-484.

Bresnahan, T. F. (1999). Computerization and wage dispersion: An analytical reinterpretation. Economic Journal, 109, 390-415.

Bresnahan, T., Brynjolfsson, E., \& Hitt, L. (2002). Information technology, workplace organization, and the demand for skilled labor: Firm-level evidence. Quarterly Journal of Economics, 117, 339-376.

Brynjolfsson, E., \& Hitt, L. (2000). Beyond computation: Information technology, organizational transformation and business performance. Journal of Economic Perspectives, 14, 23-48.

Butts, M. M., Hurst, C. S., \& Eby, L. T. (2013). Supervisor health and safety support: Scale development and validation. Journal of Applied Management and Entrepreneurship, 18, 97-118. 
Byron, K., \& Laurence, G. A. (2015). Diplomas, photos, and tchotchkes as symbolic self-representations: Understanding employees' individual use of symbols. Academy of Management Journal, 58, 298-323.

Campion, M. C., Campion, M. A., Campion, E. D., \& Reider, M. H. (2016). Initial investigation into computer scoring of candidate essays for personnel selection. Journal of Applied Psychology, 101, 958-975.

Cascio, W. F. (1995). Whither industrial and organizational psychology in a changing world of work? American Psychologist, 50, 928-939.

Cascio, W. F., \& Aguinis, H. (2008). Staffing twenty-first-century organizations. The Academy of Management Annals, 2, 133-165.

Cascio, W. F., \& Montealegre, R. (2016). How technology is changing work and organizations. Annual Review of Organizational Psychology and Organizational Behavior, 3, 349-375.

Chiravuri, A., Nazareth, D., \& Ramamurthy, K. (2011). Cognitive conflict and consensus generation in virtual teams during knowledge capture: Comparative effectiveness of techniques. Journal of Management Information Systems, 28, 311-350.

Colbert, A., Yee, N., \& George, G. (2016). The digital workforce and the workplace of the Future. Academy of Management Journal, 59, 731-739.

Daft, R. L., \& Lengel, R. H. (1986). Organizational information requirements, media richness and structural design. Management Science, 32, 554-571.

Davenport, T. H., \& Short, J. E. (1990). The new industrial engineering: Information technology and business process reengineering. Sloan Management Review, 31, 11-27.

Day, D. V., Fleenor, J. W., Atwater, L. E., Sturm, R. E., \& McKee, R. A. (2014). Advances in leader and leadership development: A review of 25 years of research and theory. The Leadership Quarterly, 25, 63-82.

Dewett, T., \& Jones, G. R. (2001). The role of information technology in the organization: A review, model, and assessment. Journal of Management, 27, 313-346.

Duarte, D. L., \& Snyder, N. T. (1999). Mastering virtual teams. San Francisco: Jossey-Bass.

Fitzgerald, M., Kruschwitz, N., Bonnet, D., \& Welch, M. (2014). Embracing digital technology: A new strategic imperative. MIT Sloan Management Review, 55, 1-12.

Foster, L. W., \& Flynn, D. M. (1984). Management information technology: Its effects on organizational form and function. MIS Quarterly, 8, 229-236.

Frenkel, S., Korczynski, M., Donoghue, L., \& Shire, K. (1995). Re-constituting work: Trends towards knowledge work and info-normative control. Work, Employment and Society, 9, 773-796.

Frey, C. B. \& Osborne, M. A. (2017). The future of employment: How susceptible are jobs to computerization? Technological Forecasting and Social Change, 114, 254-280.

Gajendran, R. S., \& Harrison, D. A. (2007). The good, the bad, and the unknown about telecommuting: Meta-analysis of psychological mediators and individual consequences. Journal of Applied Psychology, 92, 1524-1541.

Gallupe, R., Dennis, A., Cooper, W., Valacich, J., Bastianutti, L., \& Nunamaker, J. (1992). Electronic brainstorming and group size. Academy of Management Journal, 35, 350-369.

Gilson, L. L., Maynard, M. T., Young, N. C. J., Vartiainen, M., \& Hakonen, M. (2015). Virtual teams research: 10 years, 10 themes, and 10 opportunities. Journal of Management, 41, 1313-1337. 
Gioia, D. A., Corley, K. G., \& Hamilton, A. L. (2013). Seeking qualitative rigor in inductive research notes on the Gioia methodology. Organizational Research Methods, 16, 15-31.

Golden, T. D., \& Veiga, J. F. (2005). The impact of extent of telecommuting on job satisfaction: Resolving inconsistent findings. Journal of Management, 31, 301-318.

Golden, T. D., \& Veiga, J. F. (2008). The impact of supervisor-subordinate relationships on the commitment, job satisfaction and performance of virtual workers. The Leadership Quarterly, 19, 77-88.

Haas, M. R., Criscuolo, P., \& George, G. (2015). Which problems to solve? Online knowledge sharing and attention allocation in organizations. Academy of Management Journal, 58, 680-711.

Hertel, G., Geister, S., \& Konrad, U. (2005). Managing virtual teams: A review of current empirical research. Human Resource Management Review, 15, 69-95.

Hoch, J. E., \& Kozlowski, S. W. (2014). Leading virtual teams: Hierarchical leadership, structural supports, and shared team leadership. Journal of Applied Psychology, 99, 390-403.

Joshi, A., Lazarova, M. B., \& Liao, H. (2009). Getting everyone on board: The role of inspirational leadership in geographically dispersed teams. Organization Science, 20, 240-252.

Kayworth, T. R., \& Leidner, D. E. (2001). Leadership effectiveness in global virtual teams. Journal of Management Information Systems, 18, 7-40.

Kelliher, C. \& Anderson, D. (2010). Doing more with less? Flexible working practices and the intensification of work. Human Relations, 63, 83-106.

Landis, J. R., \& Koch, G. G. (1977). The measurement of observer agreement for categorical data. Biometrics, 33, 159-174.

Leonardi, P. M. (2007). Activating the informational capabilities of information technology for organizational change. Organization Science, 18, 813-831.

Leslie, L. M., Manchester, C. F., Park, T., \& Mehng, S. A. (2012). Flexible work practices: A source of career premiums or penalties? Academy of Management Journal, 55, 1407-1428.

Lewis, W., Agarwal, R., \& Sambamurthy, V. (2003). Sources of influence on beliefs about information technology use: An empirical study of knowledge workers. MIS Quarterly, 27, 657-678.

Lorinkova, N. M., Pearsall, M. J., \& Sims, H. P., Jr. (2013). Examining the differential longitudinal performance of directive versus empowering leadership in teams. Academy of Management Journal, 56, 573-596.

Malhotra, A., Majchrzak, A., \& Rosen, B. (2007). Leading virtual teams. The Academy of Management Perspectives, 21, 60-70.

Mannering, J. S. \& Mokhtarian, P. L. (1995). Modeling the choice of telecommuting frequency in California: An exploratory analysis. Technological Forecasting and Social Change, 49, $49-73$.

Martins, L. L., Gilson, L. L., \& Maynard, M. T. (2004). Virtual teams: What do we know and where do we go from here? Journal of Management, 30, 805-835.

Mazmanian, M. (2013). Avoiding the trap of constant connectivity: When congruent frames allow for heterogeneous practices. Academy of Management Journal, 56, 1225-1250.

Mazmanian, M., Orlikowski, W. J., \& Yates, J. (2005). Crackberries: The social implications of ubiquitous wireless email devices. In C. Sorenson, K. Yoo, K. Lyytinen \& J. I. DeGross (Eds.), Designing ubiquitous information environments: Socio-technical issues and challenges (pp. 337-344). New York: Springer. 
McAfee, A., \& Brynjolfsson, E. (2012). Big data: The management revolution. Harvard Business Review, 90, 60-68.

McCann, J., Selsky, J., \& Lee, J. (2009). Building agility, resilience and performance in turbulent environments. People \& Strategy, 32, 44-51.

Oldham, G. R., \& Da Silva, N. (2015). The impact of digital technology on the generation and implementation of creative ideas in the workplace. Computers in Human Behavior, 42, 5-11.

Oldham, G. R., \& Hackman, J. R. (2010). Not what it was and not what it will be: The future of job design research. Journal of Organizational Behavior, 31, 463-479.

Olszewski, P. \& Mokhtarian, P. (1994). Telecommuting frequency and impacts for State of California employees. Technological Forecasting and Social Change, 45, 275-286.

Orlikowski, W. J. \& Robey, D. (1991). Information technology and the structuring of organizations. Information Systems Research, 2, 143-169.

Parker, S. K., Van den Broeck, A., \& Holman, D. (2017). Work design influences: A synthesis of multilevel factors that affect the design of jobs. Academy of Management Annals, 11, 267-308.

Parker, S. K., Wall, T. D., \& Cordery, J. L. (2001). Future work design research and practice: Towards an elaborated model of work design. Journal of Occupational and Organizational Psychology, 74, 413-440.

Patterson, M. G., West, M. A., Shackleton, V. J., Dawson, J. F., Lawthom, R., Maitlis, S., \& Wallace, A. M. (2005). Validating the organizational climate measure: Links to managerial practices, productivity and innovation. Journal of Organizational Behavior, 26, 379-408.

Perlow, L. A., Okhuysen, G. A., \& Repenning, N. P. (2002). The speed trap: Exploring the relationship between decision making and temporal context. Academy of Management Journal, 45, 931-955.

Pfeffer, J. (2013). You're still the same: Why theories of power hold over time and across contexts. The Academy of Management Perspectives, 27, 269-280.

Pratt, M. G. (2008). Fitting oval pegs into round holes: Tensions in evaluating and publishing qualitative research in top-tier North American journals. Organizational Research Methods, 11, 481-509.

Raghuram, S., \& Wiesenfeld, B. (2004). Work-nonwork conflict and job stress among virtual workers. Human Resource Management, 43, 259-277.

Reyt, J.-N., \& Wiesenfeld, B. M. (2015). Seeing the forest for the trees: Exploratory learning, mobile technology, and knowledge workers' role integration behaviors. Academy of Management Journal, 58, 739-762.

Serban, A., Yammarino, F. J., Dionne, S. D., Kahai, S. S., Hao, C., McHugh, K. A., \& Peterson, D. R. (2015). Leadership emergence in co-located and virtual teams: A multilevel model with agent-based simulations, quasi-experimental and experimental tests. The Leadership Quarterly, 26, 402-418.

Shim, J. P., Warkentin, M., Courtney, J. F., Power, D. J., Sharda, R., \& Carlsson, C. (2002). Past, present, and future of decision support technology. Decision Support Systems, 33, 111-126.

Sinha, K. K., \& Van de Ven, A. H. (2005). Designing work within and between organizations. Organization Science, 16, 389-408.

Standen, P., Daniels, K., \& Lamond, D. (1999). The home as a workplace: Work-family interaction and psychological well-being in telework. Journal of Occupational Health Psychology, 4, 368-381. 
Straus, S. G., \& McGrath, J. E. (1994). Does the medium matter: The interaction of task type and technology on group performance and member reactions. Journal of Applied Psychology, 79, 87-97.

Tarafdar, M., Tu, Q., Ragu-Nathan, B. S., \& Ragu-Nathan, T. S. (2007). The impact of technostress on role stress and productivity. Journal of Management Information Systems, 24, 301-328.

Van Knippenberg, D., Dahlander, L., Haas, M. R., \& George, G. (2015). Information, attention, and decision making. Academy of Management Journal, 58, 649-657.

Wang, P., \& Walumbwa, F. O. (2007). Family-friendly programs, organizational commitment, and work withdrawal: The role of transformational leadership. Personnel Psychology, 60, 397-427.

Youssef, C. M., \& Luthans, F. (2007). Positive organizational behavior in the workplace: The impact of hope, optimism, and resiliency. Journal of Management, 33, 774-800.

Zuboff, S. (1988). In the age of the smart machine: The future of work and power. New York: Basic books.

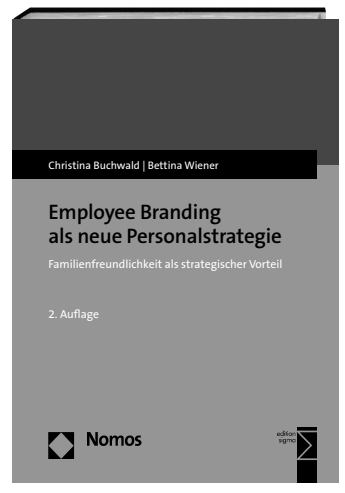

\section{Edition Sigma}

\section{Employee Branding als neue Personalstrategie}

Familienfreundlichkeit als strategischer Vorteil

By Christina Buchwald and Bettina Wiener

$2^{\text {nd }}$ edition 2018, 81 pp., pb., $€ 22.00$

ISBN 978-3-8487-4731-3

eISBN 978-3-8452-8997-7

nomos-shop.de/37660

In German language

If companies want to attract prospective managers, they need to consider how young academics' priorities in life have changed. The second edition of this volume highlights the new priorities in the lives of chemistry and pharmacy graduates and undergraduates, the highest of which is reconciling work and private life. 